\title{
SUGGESTED METHODS FOR DETERMINING RESIDUAL TRITIUM IN PROCESS BEDS (U)
}

by J.S. Holder

Westinghouse Savannah River Company

Savannah River Site

Aiken, South Carolina 29808

Other Authors:

This paper was prepared in connection with work done under Contract No. DE-AC09-89SR18035 with the U. S. Department of Energy. By acceptance of this paper, the publisher and/or recipient acknowledges the U.S. Government's right to retain a nonexclusive, royalty-free license in and to any copyright covering this paper, along with the right to reproduce and to authorize others to reproduce all or part of the copyrighted paper. 


\title{
WESTINGHOUSE SAVANNAH RIVER COMPANY Sa vanNaH RIVER TeChNOLOGY CENTER
}

\author{
Suggested Methods for Determining Residual Tritium \\ in Process Beds (U)
}

29.October.1992

Westinghouse Savannah River Company Savannah River Site Aiken, SC 29808

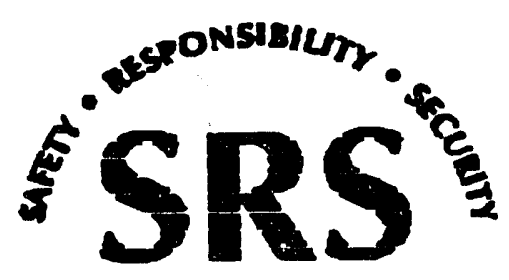




\section{DISCLAIMER}

This work was prepared as an account of work sponsored by an agency of the United States Government. Neither the United States Government nor any agency thereof, nor any of their employees, makes any warranty, express or implied, or assumes any legal liability or responsibility for the accuaracy, completeness, or usefulness of any information, apparatus, product, or process disclosed, or represents that its use would not infringe privately owned rights. Reference herein to any specific commercial product, process, or service by trade name, trademark, manufacturer or otherwise does not necessarily constitute or imply its endorsement, recommendation, or favoring by the United States Government or any agency thereof. The views and opinions of authors expressed herein do not necessarily reflect those of the United States Government or any agency thereof. 
29.October.1992

To: J. R. Knight, 773-A

From: J. S. Hölder, 773-A

Suggested Methods for Determining Residual Tritium in Process Beds (U)

\section{SUMMARY}

This memorandum has been written as a response to an H-Area EH Issue \#3 milestone (SRTC FY93 Controlled Milestone 15C70) which requires WSRC to "develop methodology for determining residual tritium in process equipment". An estimate of the tritium residing in process equipment sent for disposal must be reported on a Waste Stream Characterization Form. Currently, these estimates are crude and their technical bases are not well documented. The process equipment addressed in this report may be divided into two categories, routine and non-routine, based on their generation frequency. Magnesium Beds, Uranium Beds, and Gold Traps are regularly sent for disposal depending on the process load; Zeolite Beds and Catalyst Beds are rarely removed from the Tritium Facilities, as they may be regenerated.

In general, there are two main sources of residual tritium, that which resides in hydroxyl groups on internal surfaces and deposits, and that which has permeated the stainless steel walls and components. The tritiated hydroxyl groups may be exchangeable with gas phase deuterium, and minimized by oxidation at elevated temperatures. The tritium which has diffused into stainless steel is difficult to remove and amounts to a minor portion of the total tritium heel; this value may be calculated by a proven computer program and is on the order of $\hat{i}-5 \mathrm{Ci}$ per bed.

Zeolite Beds are a unique case, as the packing material contains a substantial portion of crystalline hydrate $\left(2 \%\right.$ by weight), even after bake out at $500^{\circ} \mathrm{C}$. The solid state hydrate will assimilate tritium from adsorbed waters, and calculations show a typical Z-bed may contain $50,000 \mathrm{Ci}$ of residual tritium. It is proposed that a calorimeter be designed and constructed to measure the tritium in Z-beds directly, and that steps be taken to reduce the residual tritium by extraction with deuterated water. Fortunately, the service life for Z-beds is long, but the estimates of "nominal" residual tritium in Z-beds which have been sent for disposal may be low by two orders of magnitude.

An experimental program to collect data on the form and quantity of residual tritium in process equipment is necessary to improve on the current "nominal" estimates and calculations of residual tritium. Direct methods of analysis, such as sampling and scintillation counting or calorimetry, would be preferred. However, the costs of worker exposure and the wastes created by such programs must be weighed against the potential benefits. In the meantime, recommendations are included here to minimize the residual tritium in process equipment being sent for disposal.

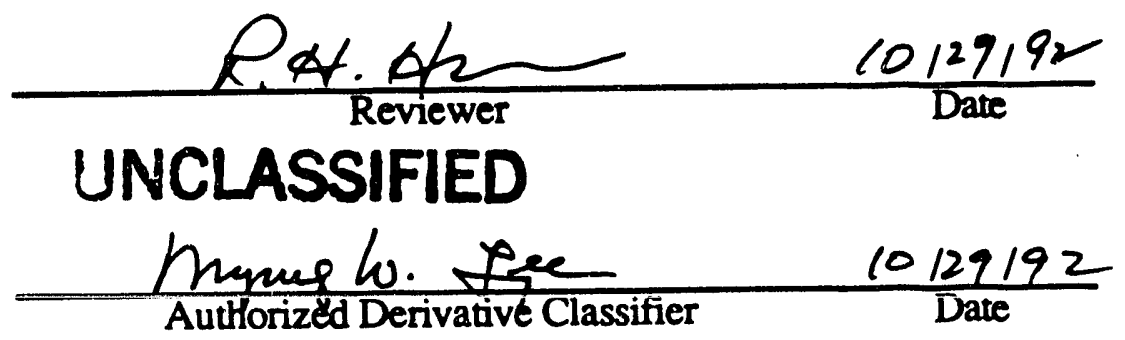

Authorized Derivative Classifier Date

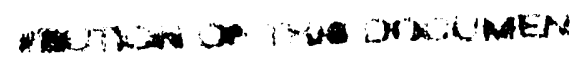

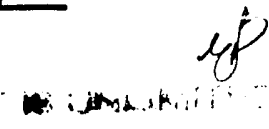




\section{INTRODUCTION}

This memorandum has been written as a response to an H-Area EH Issue \#3 milestone which requires WSRC to "develop methodology for determining residual tritium in process equipment".1 The Tritium Facilities generate several forms of tritium contaminated equipment which are periodically removed from the process and sent for disposal. An estimate of the tritium residing in that equipment must be reported on a Waste Stream Characterization Form to ensure the annual tritium waste disposal limit of $100,000 \mathrm{Ci}$ is not exceeded. Currently, these estimates are crude and their technical bases are not well documented.

The process equipment addressed in this report may be divided into two categories, routine and non-routine, based on their generation frequency. Specifically, Magnesium Beds, Uranium Beds, and Gold Traps are routinely removed from the process for disposal at a rate determined by the processing load. On the other hand, the disposal of Zeolite Beds and Catalyst Beds is non-routine, as these beds are regenerated within the Tritium Facilities and may be utilized for indefinite periods of time.

In this report, each of these equipment types is handled in a separate section. The routine waste types will be discussed first. An introductory paragraph states the lo sation, function, generation rate, and current estimate of residual tritium in each equipment type. Functional details and theories of operation are given in the background subsections. Methodologies and specific recommendations are described in subsequent subsections. Suggestions are made for improving the basis for estimating the residual tritium in prosess equipment and for minimizing the amount of tritium sent for disposal.

\section{Magnesium (Mg) BEDS}

Mg-beds are a routine solid Low Level Waste ${ }^{2}$ generated in the existing Z-bed Recovery operations in $232-\mathrm{H}$. The function of a Mg-bed is to crack waters at $\approx 500^{\circ} \mathrm{C}$, which were desorbed from a Z-bed, in a recirculating process loop. During normal operations, Mg-beds are replaced every 3-4 weeks. The current estimate of residual tritium in a $\mathrm{Mg}$-bed is $500 \mathrm{Ci}$.

\section{BACKGROUND}

The Mg-bed consists of a stainless steel pipe, filled with Mg turnings (chips), with an internal resistance heater and an axial thermowell; inlet gases are piped to the bottom of the bed, with a baffled and water cooled outlet at the top of the bed. A heat-shielded stainless steel vacuum jacket enclosure surrounds the $\mathrm{Mg}$-bed and provides an evacuated secondary confinement. $\mathrm{Mg}$-beds are used to crack waters at elevated temperatures. This reduction of gaseous water liberates elemental hydrogen gases $\left(\mathrm{H}_{2}, \mathrm{D}_{2}, \mathrm{~T}_{2}, \mathrm{HD}, \mathrm{HT}\right.$, and DT), while irreversibly forming magnesium oxide (MgO). For example,

$$
\mathrm{DTO}(\mathrm{g})+\mathrm{Mg}(\mathrm{s}) \rightarrow \mathrm{MgO}(\mathrm{s})+\mathrm{DT}(\mathrm{g}) \text {, at } 500^{\circ} \mathrm{C} \text {. }
$$


In practice, $60-70 \%$ of the theoretical yield is realized before the bed becomes inactive, due to inaccessibility of some of the $\mathrm{Mg}$ to gas phase reactants. Each $\mathrm{Mg}$-bed reduces $\approx 42.00 \mathrm{~L}$ (at STP) or $\approx 188$ moles of water vapors before it is removed from the process.

There are three methods for determining if a Mg-bed should be removed from the process: (1) flow plugged: loose MgO flakes may plug the bed, as indicated by a differential pressure $\geq 300$ torr across the bed; (2) inactive: very little pressure rise is observed during Z-bed Recovery operations; and (3) calculation: Z-bed Recovery pressure and temperature data may be used to calculate when $65 \%$ of the $\mathrm{Mg}$ has been consumed. When a $\mathrm{Mg}$-bed is removed from the process, it is evacuated and backfilled with Ar at least three times while at temperatures $\geq 250^{\circ} \mathrm{C}$. The bed is then cooled to room temperature and backfilled to $\approx 750$ torr with Ar before being opened to air and capped with blank flanges (n.b., the inlet and outlet ports are not valved).

A depleted or inactive $\mathrm{Mg}$-bed may not be recovered, as reaction (1) is irreversible. Rather, spent $\mathrm{Mg}$-beds are flushed with Ar, removed from the process, sealed inside stainless steel canisters and stored as solid Low Level Waste. Potential sources of residual tritium in $\mathrm{Mg}$-beds include tritium bound as hydroxyl groups on the internal container surfaces and in partially oxidized $\mathrm{Mg}$ [i.e., $\mathrm{Mg}(\mathrm{OT})_{2}$ ], as well as tritium which has permeated the stainless steel container walls.

\section{METHODS FOR DETERMINING RESIDUAL TRITIUM N MAGNESIUM BEDS}

In order to improve on the $500 \mathrm{Ci}$ estimate of residual tritium in a $\mathrm{Mg}$-bed, it will be necessary to collect some data. If tritium resides in the form of hydroxyl groups on the internal stainless steel surfaces and as $\mathrm{Mg}(\mathrm{OT})_{2}$ type species, then it may exchange with gas phase deuterium. A series of flushes with an $A r / D_{2}$ mixture could be analyzed by mass spectroscopy to determine the effectiveness of the exchange mechanism by quantifying the amount of tritium appearing in the gas phase. This data would allow the amount of exchangeable tritium to be determined, and could be accomplished in the existing Z-bed recovery process loop with little chance of worker exposure or environmental release. The quantity of this form of residual tritium may be on the order of $100 \mathrm{Ci}$.

A secondary source of residual tritium is that which has permeated the stainless steel walls of the Mg-bed. As the process conditions are well defined for the operation of Mg-beds, the amount of tritium which has diffused into the stainless steel may be calculated from the Finite-Difference Program for Hydrogen Diffusion. ${ }^{3}$ This value may be on the order of several $\mathrm{Ci}$, due in large part to the relatively high operating temperature for $\mathrm{Mg}$-beds and their wetting with gas phase tritium over extended periods of time (for a more complete discussion of tritium in stainless steel, see the section on Gold Traps).

\section{RECOMMENDATIONS FOR DISPOSAL OF MAGNESIUM BEDS}

Without undertaking an experimental program to collect data on the form and quantity of tritium in depleted Mg-beds, it is not possible to improve on the current estimate of residual tritiuni in these beds. However, from an examination of the presently employed processing conditions, it may be concluded that the $500 \mathrm{Ci}$ estimate is conservative. In addition, the following suggestions may reduce the amount of residual tritium in depleted $\mathrm{Mg}$-beds, and are meant to be carried out prior to the line break for removing the bed from the process. 
- Flush depleted $\mathrm{Mg}$-bed at operating temperature $\left(500^{\circ} \mathrm{C}\right)$ with dry $\operatorname{Ar}(\mathrm{g})$ until tritium is not detectable in the gas phase.

- Flush depleted $\mathrm{Mg}$-bed at operating temperature $\left(500^{\circ} \mathrm{C}\right)$ with dry $\mathrm{D}_{2}(\mathrm{~g})$ until tritium is not detectable in the gas phase.

- Flush depleted $\mathrm{Mg}$-bed at operating temperature $\left(500^{\circ} \mathrm{C}\right)$ with dry air $\left[\mathrm{O}_{2}(\mathrm{~g})\right]$ to complete the oxidation of all exposed surfaces, and thereby eliminate hydroxide groups which could retain tritium.

\section{URANIUM (U) BEDS}

U-beds are a routine solid Low Level Waste ${ }^{2}$ generated in three process areas within the existing Tritium Facilities: Extraction and Primary Separation in 232-H, and Unloading in 234-H. (n.b., U-beds will also be generated in $233-\mathrm{H}$ in the future.) Operated at $\approx 450^{\circ} \mathrm{C}$, U-beds crack waters, which may be present in the process gas, to produce elemental hydrogen isotopes and uranium oxides. U-beds may remain in service for up to two years, depending on the processing load. The current estimate of residual tritium in a U-bed is $500 \mathrm{Ci}$.

\section{BACKGROUND}

U-beds are configured similar to $\mathrm{Mg}$-beds, and are functionally identical. The U-bed consists of stainless steel pipe, filled with U turnings (chips), with an internal resistance heater and an axial thermowell; inlet gases are piped to the bottom of the bed, with an outlet at the top of the bed; both the inlet and outlet are water cooled. A heat shielded stainless steel vacuum jacket enclosure surrounds the U-bed and provides an evacuated secondary confinement.

The oxidation of $U$ is complex, involving several pathways, and many stoichiometries are possible:

$$
13 \mathrm{DTO}(\mathrm{g})+5 \mathrm{U}(\mathrm{s}) \rightarrow \mathrm{UO}_{2}(\mathrm{~s})+\mathrm{UO}_{3}(\mathrm{~s})+\mathrm{U}_{3} \mathrm{O}_{8}(\mathrm{~s})+13 \mathrm{DT}(\mathrm{g}) .
$$

It is thus difficult to predict the ultimate capacity of a U-bed. Unlike $\mathrm{MgO}$, the crystal structures of uranium oxides are not well matched to that of the parent metal, allowing the oxidized material to slough off and exposing fresh $U(s)$. This property, along with the higher atomic ratios of oxygen to metal, gives U-beds a larger capacity than $\mathrm{Mg}$-beds. Each U-bed may reduce $\approx 5600 \mathrm{~L}$ (at STP) or $\approx 250$ moles of waters.

As it is not possible to calculate the end-of-life for a U-bed, it is necessary to monitor the down stream gases for waters to determine when a U-bed has reached its end-of-life. Since U-beds are backed by Z-beds, a temperature rise on the downstream Z-bed indicates waters are being adsorbed and that the "J-bed ; no longer effective. When a U-bed has become depleted, it is evacuated and backf led with Ar at least three times while at temperatures $\geq 250^{\circ} \mathrm{C}$; the bed is then cooler. to room temperature, backfilled to $\approx 750$ torr with Ar, valved off, and removed from the process. 
The oxides produced in reaction (2) are highly stable, making recovery of U-beds impractical. Spent U-beds are removed from the process, sealed inside stainless steel canisters and stored as solid Low Level Waste. Potential sources of residual tritium in U-beds include tritium bound as hydroxyl groups on the internal container surfaces and as tritiated uranium hydroxide groups. Tritium which has permeated into the stainless steel container also contributes to the tritium heel.

\section{METHODS FOR DETERMINING RESIDUAL TRITIUM IN URANIUM BEDS}

As in the case of $\mathrm{Mg}$-beds, it will be necessary to do some sampling in order to improve on the current estimate of residual tritium in depleted U-beds. Again, if tritium resides in the form of hydroxyl groups on the surfaces of the container and/or the uranium oxide, then it may be possible to exchange it with gas phase deuterium. A series of flushes with an $\mathrm{Ar} / \mathrm{D}_{2}$ mixture could be analyzed by mass spectroscopy to determine the effectiveness of the exchange mechanism by quantifying the amount of tritium appearing in the gas phase. This data would allow the amount of exchangeable tritium to be determined, and could be accomplished with little chance of worker exposure or environmental release. The quantity of this form of residual tritium may be on the order of $100 \mathrm{Ci}$.

A secondary source of residual tritium is that which has permeated into the stainless steel walls of th: U-bed. As the process conditions are well defined for the operation of U-beds, the amount of tritium which has diffused into the stainless steel may be calculated from the Finite-Difference Program for Hydrogen Diffusion. ${ }^{2}$ This value may ie on the order of several $\mathrm{Ci}$, due in large part to the relatively high operating temperature for U-beds and their wetting by gas phase tritium over extended periods of time (for a more complete discussion of tritium in stainless steel, see the section on Gold Traps).

\section{RECOMMENDATIONS FOR DISPOSAL OF URANIUM BEDS}

Without undertaking an experimental program to collect data on the form and quantity of tritium in depleted U-beds, it is not possible to improve on the current estimate of residual tritium in these beds. However, from an examination of the presently employed processing conditions, it may be concluded that the $500 \mathrm{Ci}$ estimate is conservative. In addition, the following suggestions may reduce the amount of residual tritium in depleted U-beds, and are meant to be carried out prior to the line break for removing the bed from the process.

- Flush depleted U-bed at operating temperature $\left(450^{\circ} \mathrm{C}\right)$ with dry $\operatorname{Ar}(\mathrm{g})$ until tritium is not detectable in the gas phase.

- Flush depleted U-bed at operating temperature $\left(450^{\circ} \mathrm{C}\right)$ with dry $\mathrm{D}_{2}(\mathrm{~g})$ until tritium is not detectable in the gas phase.

- Flush depleted U-bed at operating temperature $\left(450^{\circ} \mathrm{C}\right)$ with dry air $\left[\mathrm{O}_{2}(\mathrm{~g})\right]$ to complete the oxidation of all exposed surfaces, and thereby eliminate hydroxide groups which could retain tritium. 


\section{GOLD (AU) TRAPS}

Au-traps are a routine solid Mixed Waste ${ }^{2}$ generated in the Tritium Facilities, $232-\mathrm{H}$ and 234-H. Au-traps are contaminated with both hazardous mercury $(\mathrm{Hg})$ and radioactive tritium, which make them a Mixed Waste. The primary purpose of Au-traps is the removal of $\mathrm{Hg}$ vapors from process gases by condensation at low temperature, followed by amalgamation with Au at room temperature. Au-traps are removed from service at a frequency determined by processing conditions, generally after $2-4$ years. A recent estimate of residual tritium in Au-traps is $\leq 200 \mathrm{Ci}$ per trap. ${ }^{4}$

\section{BACKGROUND}

A Gold Trap is composed of a 2" O.D. x 38" long stainless steel pipe, flanged top and bottom, with an axial rod suspending a series of stainless steel screen trays. Crumpled balls of $\mathrm{Au}$ foil are suspended between the trays. The external surface of the pipe is surrounded by a polyurethane insulated "dewar" for cryogenic cooling with liquid nitrogen (LN) or liquid Freon®. Process gas flows through the trap from bottom to top. Au-traps are employed to purify the feed for Cryogenic Distillation in 232-H, and the Loading Lines and Product Evacuation in 234-H.

During their lifetime, Au-traps may be exposed to a variety of gaseous mixtures of inerts $\left(\mathrm{N}_{2}, \mathrm{Ar}, \mathrm{He}\right)$ and hydrogen isotopes, with total pressures of up to several atmospheres, but generally sub-atmospheric. Spent Au-rraps are capped with blank flanges, placed into a plastic bag, and packed into a stainless steel container which is welded closed. Tritium contamination of Au-traps may occur in three distinct locations: 1) the gold foil and $\mathrm{Au}-\mathrm{Hg}$ amalgam; 2) the stainless steel pipe, rod, and trays; and 3) any oxides and other surface deposits. Let us consider each of these separately to determine where residual tritium is most likely to be found.

\section{TRITIUM IN GOLD AND MERCURY AMALGAM}

$\mathrm{Hg}$, a liquid at room temperature, readily wets and diffuses into $\mathrm{Au}$ foil to form an alloy. The solubility limit of $\mathrm{Hg}$ in Au occurs at $420^{\circ} \mathrm{C}$ with a value of $19.5 \mathrm{At} \% \mathrm{Hg} .{ }^{5}$ At room temperature the solubility has decreased to $\approx 16 \mathrm{At} \% \mathrm{Hg}$ or $\approx 16.25 \mathrm{wt} \% \mathrm{Hg}$ in Au . Thus, for a Au-trap loaded with $125 \mathrm{~g}$ of $\mathrm{Au}$, the maximum amount of $\mathrm{Hg}$ it could amalgamate would be $\approx 20.3 \mathrm{~g}$ at room temperature. Any $\mathrm{Hg}$ condensed in the Au-trap in excess of this amount would be in the form of pure liquid $\mathrm{Hg}$. The solubility of tritium in $\mathrm{Hg}$ is $\approx 4 \mu \mathrm{Ci} / \mathrm{kg}$, from the analysis of $\mathrm{Hg}$ in Sprengel pumps. ${ }^{6}$ If we assume the same solubility of tritium in the $\mathrm{Hg}-\mathrm{Au}$ amalgam as in $\mathrm{Hg}$, then the amount of tritium in a fully amalgamated $\mathrm{Au}$-trap at saturation would be given by

$$
(125 \mathrm{~g}+20.3 \mathrm{~g})(4 \mu \mathrm{Ci} / \mathrm{kg})\left(10^{-3} \mathrm{~g} / \mathrm{kg}\right)=0.58 \mu \mathrm{Ci} \text {. }
$$

The above result over-estimates the actual situation due to the gross approximations which were made. Process experience shows that less than $25 \%$ of the Au foil is discolored by amalgamation at the time of trap removal7 (prior to 1985, amalgamated Au was removed from the traps, replaced with fresh Au foil, and the trap returned to service). This would leave $\approx 75 \%$ of the Au in the elemental form, and Au is not known to form a hydride under any condition. Further, we have assumed the amalgam has the same tritium saturaiion concentration as pure $\mathrm{Hg}$, which should be a conservative estimate. Regardless, the value of $0.58 \mu \mathrm{Ci}$ calculated in equation (3) for residual tritium in Au foil of the Au-trap is small. 


\section{TRITIUM IN STAINLESS STEEL}

Au-traps are constructed of stainless steel parts: the pipe vessel, central rod, and screened trays, all of which are wetted with process gas and are subject to hydrogen isotope permeation. The diffusion of $H, D$, and $T$ into stainless steel is highly temperature dependent and, to a lesser extent, a function of the hydrogen isotope partial pressure. When the chemical potential (read "concentration") of a hydrogen isotope is higher in the stainless steel than in the gas phase, then it will accumulate in the steel. Conversely, when the chemical potential is lower in the gas phase than in the steel, hydrogen isotopes will desorb out of the solid phase. The chemical potential is calculated from the temperature, pressure, and composition of the system. Thus, from the process history, it is possible to calculate the concentration of tritium in the stainless steel components of Au-traps. Unfortunately, the process history may not be completely known and is most likely complex, covering a wide variety of partial pressures for various durations at a number of temperatures.

In order to make a reasonable estimate of the residual tritium in stainless steel, it is necessary to make some simplifying assumptions on the process conditions, and to use the Finite-Difference Program for Hydrogen Diffusion. 8 This is the same computer program as is currently employed to estimate the residual tritium in reservoirs sent for disposal. 9 If we consider only the pipe vessel, and assume the integrated plant history of a Au-trap may be equivalent to the following conditions:

$$
\begin{array}{ll}
\text { Total Pressure }=1 \mathrm{~atm}, & \text { Composition: } 50 \% \mathrm{D}_{2} \text { in } \mathrm{T}_{2}, \\
\text { Temperature }=25^{\circ} \mathrm{C}, & \text { Duration: } 365 \text { days, }
\end{array}
$$

then an estimate may be calculated. The result of a finite-difference calculation under these conditions is $\approx 2 \mathrm{Ci}$ for the residual tritium in the pipe vessel of a Au-trap. 10 This value is most likely an upper bound, as the majority of the actual exposure time with high concentrations of gas phase tritium occurs while the Au-traps are at cryogenic temperatures $\left(-40^{\circ} \mathrm{C}\right.$ for Freon 8 , and $-196^{\circ} \mathrm{C}$ for $\left.\mathrm{LN}\right)$. This may be offset in part by the steel which was neglected in this simplified calculation, e.g., the relatively high surface area stainless steel screen trays. In any case, this computation illustrates that there would appear to be much larger quantities of residual tritium in the stainless steel of a $\mathrm{Au}$-trap than in the $\mathrm{Au}$ and $\mathrm{Au}-\mathrm{Hg}$ foils inside the trap.

\section{TRITIUM IN SURFACE DEPOSITS}

Finally, tritium may be bound to surface deposits, such as metal oxides, in the Au-trap. Stainless steel is protected by chromium oxide, which is extremely stable, but iron oxides may also exist to a lesser degree. These oxides, as well as foreign deposits (dirt), may become passivated with tritiated hydroxyl groups. The extent to which such mechanisms add to the residual tritium is not known, aithough it should be small. This is due to the cleanliness required for process gas by the design agencies. This source could conceivably amount to a value on the order of that predicted for tritiated $\mathrm{Hg}$, making it negligible in comparison with the tritium calculated to be in the stainless steel.

\section{METHODS FOR DETERMINING RESIDUAL TRITIUM IN GOLD TRAPS}

From the above arguments, it is concluded that the stainless steel construction materials of Au-traps are the most likely sources of residual tritium at the time of disposal. The amount 
of tritium residing in this steel at the end-of-life of a Au-trap is completely dependent on the process history of the trap. Given this information, the tritium concentration in the stainless steel may be calculated very accurately by the Finite-Difference Program For Hydrogen Diffusion, which is currently in use here at SRS for calculating the residual tritium in reservoirs being sent for disposal.

The reconstruction of this history from Plant data may be difficult or impossible, however, special attention should be given to any times when the Au-traps were exposed to high partial pressures of tritium at room temperature (the highest temperature to which the traps are exposed). A study could be conducted during normal Plant operations over a one month period to collect temperature, pressure, and composition data on Au-traps in the various locations with the Tritium Facilities. This data could then be used to create a model to simulate the history of Au-traps and applied to the Finite-Difference Program for Hydrogen Diffusion to predict residual tritium contents of Au-traps at the time they were removed from service for disposal.

There does not appear to be another significant source of residual tritium in Au-traps. Trace amounts, on the order of $\mu \mathrm{Ci}$ per $\mathrm{kg}$, may exist in the $\mathrm{Au}-\mathrm{Hg}$ amalgam and in surface deposits, in the form of tritiated hydroxyl groups. These sources may integrate to several $\mu \mathrm{Ci}$ of tritium, which is negligible in comparison to the residual tritium in the stainless steel.

\section{RECOMMENDATIONS FOR DISPOSAL OF GOLD TRAPS}

The current estimate of residual tritium in Au-traps is $200 \mathrm{Ci}$ per trap. ${ }^{3}$ Unless a trap is saturated and $\mathrm{Hg}$ is precipitated out, the current estimate appears to be conservative and may be high by as much as two orders of magnitude. From the data now available, it would appear that an upper bound of $10 \mathrm{Ci}$ of residual tritium per trap is a more reasonable estimate, unless tritiated water or oil is also present.

Every effort should be made to ensure Au-traps do not contain tritiated water at the time they are removed from the process for disposal. To facilitate this, the following procedures, including heating, may be undertaken prior to the line break for Au-trap replacement. Heating should not result in the release of $\mathrm{Hg}$, as the solubility of $\mathrm{Hg}$ in $\mathrm{Au}$ increases with temperature up to $420^{\circ} \mathrm{C}$.

- Flush spent Au-trap at room temperature with dry $\operatorname{Ar}(\mathrm{g})$ until tritium is not detectable in the gas phase.

- Flush spent $\mathrm{Au}$-trap at elevated temperature $\left(\approx 100^{\circ} \mathrm{C}\right)$ with dry $\operatorname{Ar}(\mathrm{g})$ until tritium is not detectable in the gas phase.

\section{ZEOLITE (Z) BEDS}

Z-beds are an infrequently generated non-routine solid Low Level Waste ${ }^{2}$ (n.b., the latest Z-bed disposal occurred in 1990). Z-beds operate at both ambient and liquid nitrogen (LN) temperatures to adsorb waters from flow through gas streams throughout the existing Tritium Facilities, and will be used in the stripper systems in 233-H. Z-beds have an 
indefinite lifetime, and may remain in service for more than 10 years. The current estimate of residual tritium in a $\mathrm{Z}$-bed is $500 \mathrm{Ci}$.

\section{BACKGROUND}

The Z-bed consists of a vertically oriented stainless steel pipe, filled with molecular sieve (zeolite) pellets, with an axial thermowell running the length of the bed; the water cooled gas inlet leads to the top of the bed, and the outlet is piped up from the bottom of the bed. In 232- $\mathrm{H}$ and $234-\mathrm{H}, \mathrm{Z}$-beds come in three sizes and two types of zeolite packing materials are used. In the Stripper systems, 6" O.D. $x$ 35" long beds are employed with $3 \mathrm{~A}$ molecular sieve pellets. Whereas the 4" O.D. beds may be 24 " or 35" long and are packed with $5 \mathrm{~A}$ molecular sieve pellets. ${ }^{11}$ These beds are used in the Cryogenic Distillation and Diffuser feed streams.

The heat of adsorption is released to the bed as waters are removed from the gas phase and immobilized on the zeolite surfaces. An adsorption front moves down the bed, which may be monitored by a temperature rise on thermocouples located along the length ot the thermowell, as the zeolite pellets become saturated with waters. Tritiated waters tend to maintain saturated portions of the Z-bed at elevated temperatures due to the heat released by the beta decay of tritium. When the temperature front reaches a lower portion of the zeolite, the Z-bed is removed from service and sent to Z-bed Recovery for desorption. However, in certain process locations, the Z-beds may become completely saturated with waters before they are removed for regeneration.

Regeneration of Z-beds by desorption of waters takes place in the Z-bed Recovery process loop. The Z-bed is heated in a furnace to $250^{\circ} \mathrm{C}$, while dry Ar or process gas is circulated up through the Z-bed (n.b., this is the reverse of the normal operating flow direction) in a closed loop which includes a Mg-bed to crack the desorbing waters. The loop pressure is allowed to rise to a preset limit, before the recovered gases are pumped into a collection tank. When the loop evacuation reaches a lower pressure limit, the system is valved back into the recirculating mode and the pressure begins to rise again. The composition of the gases in the collection tank is determined by mass spectroscopy, which allows the abundance of $H, D$, and $T$ recovered to be quantified. The $Z$-bed is considered to be completely regenerated when no further pressure rise is observed. The entire Recovery process may take from 2 to 10 days.

Z-beds remain in operation for many years, however their capacity will slowly decrease. The finite lifetime of a Z-bed may be attributed to mechanical breakdown of the zeolite pellets, which tend to deteriorate with adsorption/regeneration cycles. From the data recorded during Z-bed Recovery operations, the volume of waters desorbed from a bed may be calculated. This information is used to determine when a Z-bed has lost sufficient capacity to warrant its disposal. At this point, the Z-bed undergoes a final Recovery at $500^{\circ} \mathrm{C}$ to remove as much of the adsorbed waters as possible. After final Recovery, Z-beds are removed from service and stored in B-25 boxes as Low Level Waste.

The main source of residual tritium in a Z-bed sent for disposal is the surface bound hydrates in the zeolite material which were not removed during the final Recovery process. The non-volatile hydrate amounts to a significant percentage of the zeolite, $\approx 2 \%$ by weight. These surface groups are able to exchange $H, D$, and $T$ with adsorbed waters, and it is assumed that an equilibrium is established between the hydrate and the adsorbed waters. That is to say, the tritium content of the hydrate is determined by the composition of the adsorbed waters. Thus, from the mass spectroscopic analysis of the gases desorbed 
during the final recovery in the Z-bed Recovery process, the composition of the hydrate (\% tritium) may be inferred.

A secondary source of residual tritium in Z-beds is the stainless steel container. The gas phase tritium wets the stainless steel walls of the Z-bed at moderate partial pressures (10's of torr) and at temperatures up to $500^{\circ} \mathrm{C}$. The high temperatures facilitate the permeation of tritium into steels, as long as the gas phase tritium chemical potential is relatively high (see the above discussion of residual tritium in stainless steel in the section on Gold Traps). The quantity of tritium in stainless steel may be calculated using the Finite-Difference Program for Hydrogen Diffusion and the process conditions. However, this value is likely to be small for Z-beds in comparison to that found in the zeolite packing material.

\section{METHODS FOR DETERMINING RESIDUAL TRITIUM IN ZEOLLTE BEDS}

From the composition of the collection tank gases taken during the final Z-bed Recovery at $500^{\circ} \mathrm{C}$, the composition of the non-volatile surface hydrate may be inferred, where equilibrium between the adsorbed phase and the hydrate is assumed. As the mass of zeolite in a Z-bed is known, the residual tritium in the hydrate may be calculated, given that the hydrate accounts for $2 \%$ by weight of the zeolite. An example of such a calculation will illustrate this point:

Consider a 6 " Z-bed containing $10 \mathrm{~kg}$ of zeolite. If the final desorption resulted in a collection tank composition with $10 \%$ tritium by volume, then the mass of tritium in the hydrate would be:

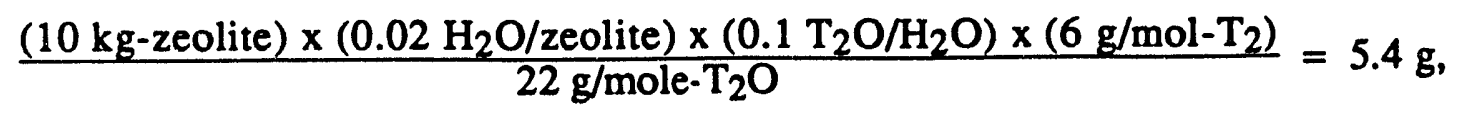

which at $9700 \mathrm{Ci} / \mathrm{g}$ translates into $\approx 52,000 \mathrm{Ci}$ of tritium activity in this hypothetical Z-bed. This calculation is prucess dependent, as each bed is exposed to different concentrations of tritiated water in the various Tritium Facility processes. The percent tritium in the Z-bed Recovery collection tank has a large range, and values up to $50 \%$ are not uncommon. It appears that this method would facilitate the accountability of substantial quantities of residual tritium on Z-beds.

In the above calculation, equilibration between the gas and solid phases is assumed. A more direct determination would involve sampling of the zeolite packing material at the time of disposal. High accuracy calorimetry would then be required to quantify the amount of tritium in the zeolite sample. Alternatively, the sample could be dissolved in an aqueous acid solution and analyzed by a scintillation counter. A drawback of these methods is the assumption the sample is representative, that is that the residual tritium is evenly distributed throughout the packing material in the Z-bed. Furthermore, any tritium in the stainless steel of the Z-bed would be neglected.

The definitive residual tritium analysis would be calorimetry on the entire Z-bed. The $5.4 \mathrm{~g}$ of tritium calculated in equation (4) would generate, at $0.3 \mathrm{Watt} / \mathrm{g}-\mathrm{T}_{2}$, approximately 1.6 Watt of heat, which is substantia' enough to be measured. The calorimetric analysis would be independent of Z-bed process history, allowing the residual tritium in any Z-bed to be determined (or at least given an upper bound depending on sensitivity). An added benefit of this technique is that it is noninvasive, minimizing both potential worker exposure and environmental release. 
Finally, it may be possible to reduce the amount of residual tritium in Z-beds being sent for disposal by exchange with $\mathrm{D}_{2} \mathrm{O}(1)$. Gas phase exchange with $\mathrm{D}_{2}$ is not expected to be effective due to the stability of the hydrate, however saturation with deuterated water should draw tritium out of the hydrated form and thereby reduce the residual tritium in a $\mathrm{Z}$-bed. The viability of this exchange could be determined in "cold" tests, where $\mathrm{D}_{2} \mathrm{O}(\mathrm{l})$ would be exchanged with protium in the hydrate. In practice, this type of exchange would generated Mg-bed waste, as tritiated waters desorbed from the Z-bed must be cracked, and this trade-off may not be desirable.

It may be concluded that the estimate of $500 \mathrm{Ci}$ of residual tritium per Z-bed is low, possibly by two orders of magnitude. Furthermore, the residual tritium in a Z-bed is highly dependent on the process history of that bed directly prior to its disposal. This fact, along with the wide variety of process conditions to which Z-beds are exposed, make the residual tritium in each Z-bed unique.

\section{RECOMMENDATIONS FOR DISPOSAL OF ZEOLITE BEDS}

- At this time, use calculations such as that given in equation (4) as a guide for estimating residual tritium in Z-beds.

- During the final desorption of the bed in the Z-bed Recovery process at $500^{\circ} \mathrm{C}$, the composition of the collection tank gases should be determined by mass spectroscopy, recorded, and retained on file. (n.b., an attempt was made to find this information for the last three Z-beds removed from service in 1990, 1988, and 1987, none of which was readily available.)

- As a long range solution to determining the residual tritium in Z-beds, it is recommended that a calorimeter be the designed and constructed.

- It may be possible to reduce the amount of residual tritium in a Z-bed by saturation with $\mathrm{D}_{2} \mathrm{O}(1)$, followed by the $\mathrm{Z}$-bed Recovery procedure at $500^{\circ} \mathrm{C}$; the benefit of this exchange must be weighed against the waste it would create, a spent $\mathrm{Mg}$-bed, and any potential worker exposure it may entail.

\section{Catalyst (CA) BEDS}

CA-beds are an infrequently generated non-routine solid Low Level Waste. ${ }^{2}$ CA-beds are employed in the stripper systems in both $232-\mathrm{H}$ and $234-\mathrm{H}$, where they operate at $500^{\circ} \mathrm{C}$ to form waters from oxygen and hydrogen isotopes in a flow through gas stream; down stream Z-beds trap the waters out of the gas stream before it is stacked. CA-beds have long service lives and remain active for many years. The current worst case estimate for residual tritium in a CA-bed is $\leq 5000 \mathrm{Ci} .12$

\section{BACKGROUND}

The CA-bed consists of a stainless steel pipe, filled with Hopcalite and Deoxo $M$ catalysts, with an internal resistance heater and an axial thermowell; inlet gases are piped to the bottom of the bed, with a water cooled outlet at the top of the bed. There is no secondary confinement, rather the CA-bed is surrounded by a thickly insulated stainless steel vessel. The catalytic process requires both gas phase oxygen and hydrogen: 


$$
2 \mathrm{DT}(\mathrm{g})+\mathrm{O}_{2}(\mathrm{~g}) \rightarrow 2 \mathrm{DTO}(\mathrm{g}),
$$

where the reaction occurs on the platinum surfaces of the Deoxo $M$ material [1-2\% $\mathrm{P} t / \mathrm{Al}_{2} \mathrm{O}_{3}$ (Engelhardt)]. For gas streams which are oxygen deficient, the Hopcalite material $\left(20 \% \mathrm{CuO}, 80 \% \mathrm{MnO}_{2}\right)$ serves as a source of uxygen to combine with hydrogen isotopes and form waters. ${ }^{13}$ The Hopcalite may be regenerated by flowing air from routine process evacuations. Theoretically, a CA-bed should remain active indefinitely, however, the platinum surfaces may become poisoned by impurities and the container is subject to normal fatigue.

When CA-beds are removed from service, they are flushed and backfilled with Ar, capped and stored in stainless steel boxes. CA-beds are classified as Mixed Waste, due to a combination of external lead shielding and internal residual tritium. The residual tritium may be in the form of hydroxide groups on the Deoxo $M$ and Hopcalite packing materials and in the stainless steel walls of the CA-bed vessel.

\section{METHODS FOR DETERMINING RESIDUAL TRITIUM IN CATALYST BEDS}

Similar to the cases of $\mathrm{Mg}$-beds and $\mathrm{U}$-beds, additional data is needed to improve on the estimate of residual tritium in a CA-bed, it will be necessary to collect some data. If tritium resides in the form of hydroxyl groups, then it may be exchangeable with gas phase deuterium. A series of flushes with an $\mathrm{Ar} / \mathrm{D}_{2}$ mixture could be analyzed by mass spectroscopy to determine the effectiveness of the exchange mechanism by quantifying the amount of tritium appearing in the gas phase. This data would allow the amount of exchangeable tritium to be determined, and could be accomplished with little chance of worker exposure or environmental release. The quantity of this form of residual tritium may be on the order of $1000 \mathrm{Ci}$.

As an example calculation, consider a CA-bed packed with $6 \mathrm{~kg}$ of Deoxo $\mathrm{M}$ catalyst, which is $2 \%$ by weight hydroxyl groups when "dry", and is in equilibrium with an $0.5 \%$ tritium gas stream. The residual tritium in this $\mathrm{CA}$-bed would be:

$$
\frac{(6000 \mathrm{~g} \text {-cat }) \times(0.02 \mathrm{OH} / \mathrm{cat}) \times\left(0.005 \mathrm{O} \mathrm{O}^{\prime} \mathrm{r} / \mathrm{OH}\right) \times(3 \mathrm{~g} / \mathrm{mol}-\mathrm{T})}{17 \mathrm{~g} / \mathrm{mol}-\mathrm{OH}}=0.11 \mathrm{~g},
$$

which at $9700 \mathrm{Ci} / \mathrm{g}$ translates into $1027 \mathrm{Ci}$. Thus, depending on the weight of Deoxo $\mathrm{M}$ catalyst in the CA-bed and the composition of the gas stream in the stripper system, a "nominal" estimate of $1000 \mathrm{Ci}$ of residual tritium in a CA-bed is reasonable.

A secondary source of residual tritium is that which has permeated the stainless steel walls of the CA-bed. As the process conditions are well defined for the operation of CA-beds, the amount of tritium which has diffused into the stainless steel may be calculated from the Finite-Difference Program for Hydrogen Diffusion. ${ }^{2}$ This value may be on the order of several $\mathrm{Ci}$, due in large part to the relatively high operating temperature for CA-beds and their wetting by gas phase tritium over extended periods of time (for a more complete discussion of tritium in stainless steel, see the section on Gold Traps).

If a depleted CA-bed did contain on the order of $5000 \mathrm{Ci}$ of tritium, it would produce $\approx 0.15$ Watt of decay heat. Due to the configuration of the CA-bed, it may be possible to do some in situ calorimetry to detect the residual tritium. It should be noted that a CA-bed is fully insulated, and is equipped with thermocouples for measuring the bed's skin and 
internal temperatures. This information could be used to set an upper bound on the residual tritium in a CA-bed.

\section{RECOMMENDATIONS FOR DISPOSAL OE CATALYST BEDS}

The generation rate of CA-beds for disposal is extremely low, and the estimate of $5000 \mathrm{Ci}$ of residual tritium is probably high, making an experimental program for determining the residual tritium in a CA-bed difficult to justify. However, the following suggestions mey reduce the amount of residual tritium in a deactivated CA-bed, and are meant to be carried out prior to the line break for removing the bed from the process.

- Flush the deactivated CA-bed at operating temperature $\left(500^{\circ} \mathrm{C}\right)$ with dry $\operatorname{Ar}(\mathrm{g})$ until tritium is not detectable in the gas phase.

- Flush the deactivated CA-bed at operating temperature $\left(500^{\circ} \mathrm{C}\right)$ with dry $\mathrm{D}_{2}(\mathrm{~g})$ until tritium is not detectable in the gas phase.

- Flush the deactivated CA-bed at operating temperature $\left(500^{\circ} \mathrm{C}\right)$ with dry air $\left[\mathrm{O}_{2}(\mathrm{~g})\right]$ to complete the oxidation of all exposed surfaces, and thereby eliminate hydroxide groups which could retain tritium.

\section{SUMMARY OF RECOMMENDATIONS}

It is recommended that the "nominal" residual tritium values for process equipment be revised, as shown in the following table, until an experimental program is implemented to determine these values analytically.

$\checkmark$

\begin{tabular}{ccc}
\hline Equipment & Current "Nominal" Value & Recommended "Nominal" Value \\
\hline Magnesium Beds & $500 \mathrm{Ci}$ & $100 \mathrm{Ci}$ \\
Uranium Beds & $500 \mathrm{Ci}$ & $100 \mathrm{Ci}$ \\
Gold Traps & $5200 \mathrm{Ci}$ & $10 \mathrm{Ci}$ \\
Zeolite Beds & $500 \mathrm{Ci}$ & $50,000 \mathrm{Ci}$. \\
Catalyst Beds & $\leq 5000 \mathrm{Ci}$ & $1000 \mathrm{Ci}$ \\
\hline
\end{tabular}

* Calculated value, dependent on the composition of the final recovery gases. 
J. R. Knight

29. October.1992

WSRC-RP-92-1260

\section{ACKNOWLEDGEMENT}

The author would like to thank the following pesple for their comments and input in the preparation and review of this report: R. L. Rabun, D. A. Dauchess, C. E. Bannister, and P. J. Rowan, Jr. from the Tritium Facilities; R. H. Hsu, T. Motyka, M. W. Lee, L. K. Heung, J. E. Klein, W. C. Mosley, A. Nobile, Jr., and J. R. Wermer from the Hydrogen Technology Section; R. A. Malstrom from the Analytical Development Section; and M. J. Morgan from the Materials Technology Section. 


\section{REFERENCES}

1SR-MD-92-001, FY 1992 Corrective Action Plan for Savannah River Site Tritium Operations, W.B. Wilson, DOE-SR, February, 1992, pp 19-20.

2OPS-TTG-900105, “Tritium Facilities Waste Characterization", P.J. Rowan and J.K. Puckett to D.J. Green, June, 1990.

3DP-1738, "Finite-Differenre Program for Hydrogen Diffusion", K.E. Kain, March, 1987.

4DPSOXWD-469, Special Test Authorization-229, "Tritium-Contaminated Gold Amalgam Disposal".

5Solubility Data Series, Vol. 29, "Mercury in Liquids, Compressed Gases, Molten Salts and Other Elements", H.L. Clever, Ed., Pergamaon Press, 1987.

6R.T. Tsugawa, J.S. Bowers, J.A. Emig, R.S. Hafner, J.L. Maienschein, A.S. Nocolosi, J. Nuclear Material 172, 239 (1990).

7DPSTWD-80-122, “Gold Trap and Mercury Reduction”, M.W. Lee to R.L. Folger, 9/29/80.

8DP-1738, "Finite-Difference Program for Hydrogen Diffusion", K.E. Kain, March, 1987.

${ }^{9}$ WSRC-RP-91-1181, "Tritium Technology Memorandum \#649, Tritium Estimates for Reservoir Burial (U)", W.L. West to M.J. Green, November; 1991.

10SRT-MTS-92-4060, "Tritium Concentration in Gold Traps", M.J. Morgan to J.S. Hölder, October, 1992.

11DPSOL 232-H-1429, "Preparing a New Zeolite Bed”, Rev. 6, 30.June.89.

12WSRC-TR-90-226, "SRS Mixed Waste Characterization Catalog for the Hazardous Waste / Mixed Waste Disposal Facility Phase I (Vaults) and Phase II (Treatment Building)", M.S. Hay, May, 1990.

13DPST-85-869, "Summary of Zeolite and Catalyst Data”, R.H. Hsu to R.D. Buley, January, 1986 (Revised). 

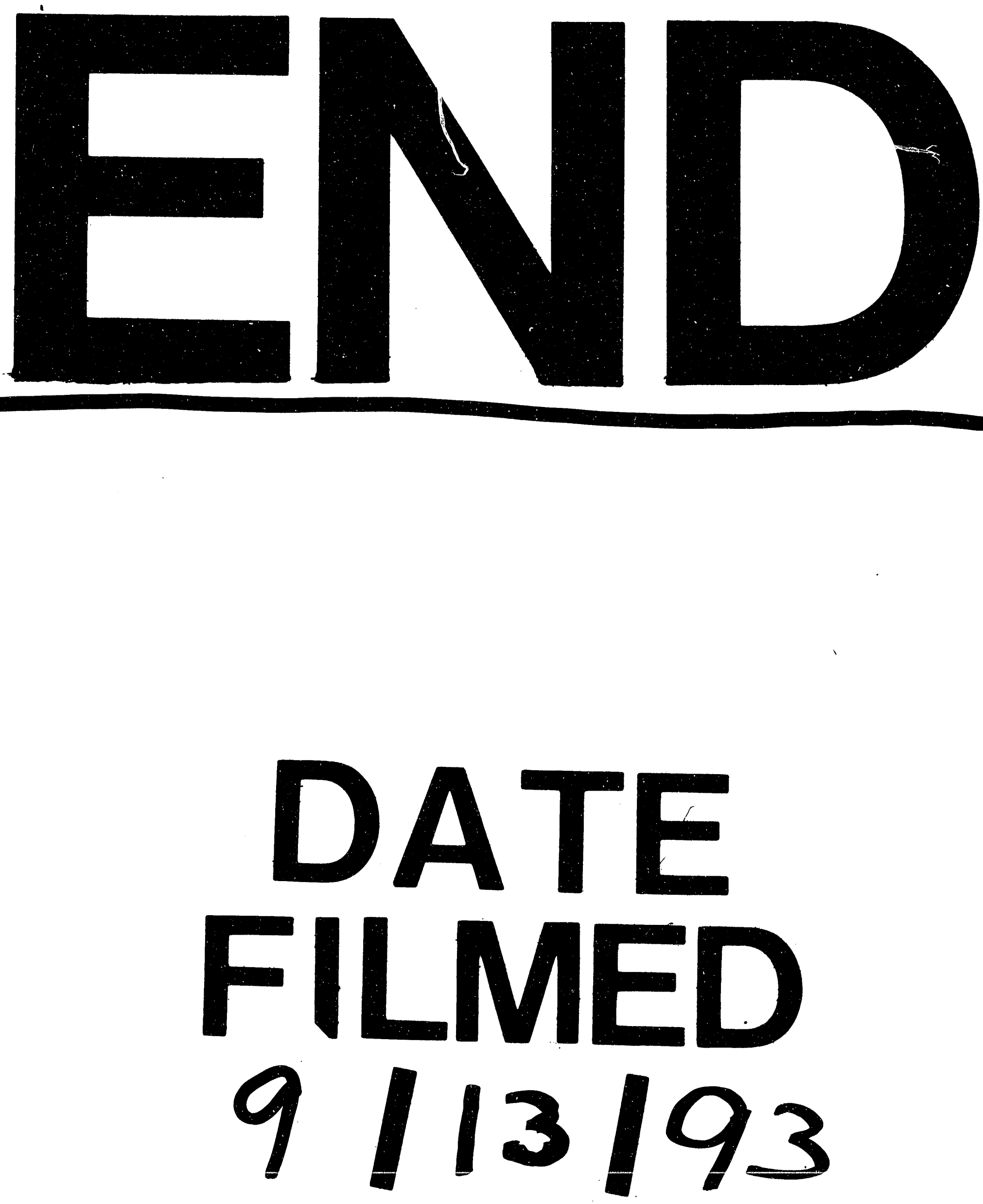


$$
\Gamma
$$

